\title{
Influence de l'élastolyse dans la physiopathologie gingivale
}

\section{Elastolysis effect in gingiva physiopathology}

\author{
A. COZLIN-MARTEL ${ }^{1}$, S. BARTHELEMI', F. ANTONICELLI ${ }^{2}$, R. GARNOTEL ${ }^{2}$, M. DECARME ${ }^{2}$, \\ C. GUILLAUME', H. KAPLAN ${ }^{1}{ }^{2}$, D. LAURENT-MAQUIN' ${ }^{1}$, W. HORNEBECK ${ }^{2}$, S. LORIMIER
}

\section{RÉSUMÉ}

Les peptides d'élastine $(\mathrm{kE})$ augmentent l'expression des MMP3 et MMP1 dans les fibroblastes gingivaux humains cultivés en 2D sur plastique alors qu'ils n'ont aucune influence sur la production d'uPA, des MMPs2, 13, 14 et des TIMPs1 et 2. L'effet de kE sur la production de MMP3 dépend du récepteur membranaire S-Gal tandis qu'il est inhibé par le lactose et reproduit par des peptides contenant la séquence VGVAPG capable de se fixer sur S-Gal. Afin d'évaluer l'implication des peptides d'élastine dans la collagénolyse, des cultures cellulaires en 3D ou lattis de collagène attaché sont utilisés : $k E$ ou le plasminogène (Plgn) seuls n'induisent pas de façon significative une collagénolyse des lattis de collagène. Toutefois, $k E$, en présence de Plgn, augmente de façon synergique la dégradation du collagène et l'activation des MMPs. Au sein des lattis en présence de peptides d'élastine, la collagénolyse serait dépendante d'une sur-expression de la cascade protéolytique MMP3/MMP1 par les fibroblastes gingivaux humains, associée à une sous-expression des TIMP1 et de TIMP2. (Med Buccale Chir Buccale 2009 ; 15: 75-85).

mots clés: fibroblastes gingivaux, métalloprotéinases matricielles, élastolyse, peptides d'élastine, collagénolyse, lattis de collagène attaché

\section{SUMMARY}

médecine

buccale

chirurgie

buccale

VOL. $15, \mathrm{~N}^{\circ} 2$ 2009

page 75

Elastin derived peptides (EDPS) were shown to increase the expression of MMP-3 and MMP1 in human gingival fibroblasts cultures while having no influence on levels of UPA, MMPs 2, 13, 14 and TIMPs1 and 2. EDPs-inducing effect on MMP-3 production was S-Gal receptor-mediated since it was significantly inhibited by lactose and reproduced by peptides containing the VGVAPG sequence recognized by this plasma membrane receptor. To assess the contribution of EDPs in collagenolysis, 3D cellular cultures or attached collagen lattices were used; EDPs or plasminogen (Plgn) alone did not significantly induced collagenolysis in attached collagen lattices. However, EDPS were found to synergize the influence of Plgn on collagen degradation and MMPs-activation. Those effects could be accounted for by EDPs-mediated up-regulation of MMP3/MMP1 cascade associated with significant downregulation of TIMP1 and TIMP2 production. (Med Buccale Chir Buccale 2009 ; 15: 75-85).

key words: gingival fibroblasts, matrix metalloproteinases, elastolysis, eElastin derived peptides, collagenolysis, attached collagen lattices

1. Unité INSERM UMR-S926 Interface Biomatériaux / Tissus Hôtes, Institut « Biomolécules » (IFR53) Faculté d'Odontologie Université de Reims Champagne-Ardenne 1 rue Maréchal Juin 51095 Reims Cedex

2. Unité CNRS UMR 6237 Institut « Biomolécules 》 (IFR53), Faculté de Médecine Université de Reims Champagne-Ardenne 51 rue Cognacq Jay 51095 Reims Cedex

- A. Cozlin-Martel et S. Barthelemi ont contribué de façon équivalente à ce travail.

Demande de tirés à part:

Sandrine Lorimier Unité INSERM UMR-S 926 Interface Biomatériaux/ Tissus hôtes IFR53 Faculté d'Odontologie Université de Reims Champagne-Ardenne 1 rue Maréchal Juin 51095 Reims Cedex 
médecine

buccale

chirurgie

buccale

VOL. $15, \mathrm{~N}^{\circ} 2$ 2009

page 76
Les maladies parodontales correspondent à une inflammation d'origine multifactorielle nécessitant la présence de bactéries spécifiques qui conduit à la destruction des tissus parodontaux ${ }^{[1]}$. La lyse matricielle engendrée résulte essentiellement d'un déséquilibre entre mécanismes protecteur et destructeur des cellules de l'hôte [2]. L'infiltrat inflammatoire est constitué de $90 \%$ de polymorphonucléaires neutrophiles (PMNs) ${ }^{[3]}$. D'autres cellules du tissu parodontal (lymphocytes, monocytes, fibroblastes...) répondent à l'agression bactérienne en sécrétant une variété de molécules pro-inflammatoires (IL1, TNF...) à l'origine de la sur-expression d'enzymes protéolytiques. L'implication des protéases de la famille des métalloprotéinases matricielles (MMPs) a été largement associée à la dégradation des constituants de la matrice extracellulaire ${ }^{[4]}$, plus particulièrement dans la destruction pathologique des tissus parodontaux ${ }^{[5]}$. Une corrélation a été établie entre le taux de collagénase active, extraite de tissus gingivaux, et le degré d'inflammation [6]. Le système plasminogène/plasmine est étroitement lié au mécanisme d'activation des MMPs ${ }^{[7]}$. Par conséquent, un ensemble complexe d'évènements ou cascade protéolytique entraîne la destruction parodontale. Enfin, le déséquilibre entre MMPs actives et leurs inhibiteurs naturels endogènes (TIMPs, serpines) favorise la dégradation tissulaire ${ }^{[8]}$.

Les enzymes secrétées possèdent une activité collagénolytique (MMPs1, 13...) mais aussi élastolytique comme les MMPs 2, 9, 12 et certaines sérine-protéinases (protéinase3 et élastase leucocytaire) ${ }^{[9]}$. Ainsi, $70 \%$ du collagène in situ est détruit après 4 à 7 jours d'accumulation bactérienne ${ }^{[3]}$ avec la lyse des fibres élastiques gingivales ${ }^{10]}$. La collagénolyse et l'élastolyse induites génèrent des fragments peptidiques dans l'environnement péricellulaire comme les peptides d'élastine appartennant aux matrikines ou « élastokines "; ces derniers sont capables de moduler le phénotype de nombreux types cellulaires [9,11]. Ils agissent sur le chimiotactisme, la prolifération et l'adhésion cellulaires, sur la mobilisation calcique intracellulaire, orientent les lymphocytes T vers une réponse immune de type TH1. Ils possèdent des propriétés pro-angiogéniques $[9,12,13]$. Ces effets sont attribués en partie à la séquence
VGVAPG, répétée 6 fois dans la tropoélastine, précurseur soluble de l'élastine. Toutefois, les peptides possédant la séquence consensus XGXXPG et adoptant une conformation en coude $B$ de type VIII, possèdent des activités biologiques ${ }^{[9,14]}$. GXXPG est largement représenté dans la tropoélastine (28 fois), certaines fibrillines, la fibronectine... ${ }^{15]}$. Enfin, les effets des peptides d'élastine sont médiés par leur liaison à une protéine membranaire, nommée S-Gal ou EBP (Elastin Binding Protein). C'est une protéine d'environ 67 kDa associée à deux autres protéines : une neuraminidase de $61 \mathrm{kDa}$, transmembranaire, et une protéine protectrice de $55 \mathrm{kDa}$. S-Gal résulte de l'épissage alternatif inactif de la $B$ galactosidase [16]. Aussi, la liaison de l'élastine ou des peptides d'élastine à l'EBP est sensible au lactose. Ce dernier possède un site de fixation de type lectine, capable d'interagir avec des résidus galactosyl, entraînant ainsi une diminution de l'affinité du récepteur pour l'élastine et sa dissociation du complexe membranaire.

Des études précédentes montrent que les peptides d'élastine stimulent la production de gélatinase $A$, de pro-MMP1 par les fibroblastes dermiques ${ }^{[14]}$, de MT1-MMP par les cellules endothéliales [13]. Par conséquent, ces " élastokines » sont sans doute capables d'activer les cascades protéolytiques de la collagénolyse.

Pour tester cette hypothèse, nous avons cultivé des fibroblastes gingivaux humains dans des cultures tridimensionnelles de collagène ou lattis de collagène utilisés comme équivalent de la lamina propria gingivale.

\section{MATÉRIEL ET MÉTHODES}

\section{Cultures cellulaires et études mor- phologiques}

Les cellules utilisées sont des fibroblastes obtenus à partir d'explants de biopsies gingivales, prélevées au cours d'intervention de chirurgie pré-prothétique sur des sujets âgés de 40 à 60 ans, non fumeurs et exempts de maladies générale ou parodontale. Tous ces prélèvements ont été réalisés en respectant les dispositions d'Helsinki.

Les fibroblastes gingivaux humains sont cultivés dans du DMEM (Dulbecco's modified Eagle's 
medium) (Life Technologies, Pasley, Ecosse) à $10 \%$ de sérum de veau fœtal, maintenu dans un incubateur à $37^{\circ} \mathrm{C}$, sous une atmosphère avec $5 \%$ de CO2. Les cellules sont utilisées entre le $4^{\mathrm{e}}$ et le $7^{\mathrm{e}}$ passages.

L'élastine insoluble est préparée à partir de ligament de nuque de veau par traitement alcalin à chaud. La kappa-élastine soluble ( $k E)$, constituée d'un mélange de peptides, est issue de l'élastine insoluble purifiée traitée par hydrolyse organoalcaline [17]. VGVAPG (Réf V1008) et VGVAPG3 sont obtenus respectivement, auprès de Sigma (Saint-Quentin, Fallavier, France) et Neosystems (Strasbourg, France). Les peptides d'élastine sont ajoutés aux cultures de fibroblastes gingivaux humains à une concentration de $100 \mu \mathrm{g} / \mathrm{ml}$ pour $\mathrm{kE}$ et de $200 \mu \mathrm{g} / \mathrm{ml}$ pour VGVAPG et VGVAPG3. Au cours de l'étude portant sur le récepteur EBP, les cellules sont prétraitées pendant 1 heure avec du lactose à une concentration de $50 \mu \mathrm{mol} / \mathrm{ml}$ avant ajout de kappa élastine $(100 \mu \mathrm{g} / \mathrm{ml})$.

Les fibroblastes sont ensemencés à confluence (200 000 cellules) dans des plaques 24 puits avec un milieu DMEM sans sérum, en l'absence ou en présence de $\mathrm{kE}$, et cultivées pendant 24 heures. Les lattis de collagène " attachés » sont réalisés selon la technique décrite par Gillery et coll. en $1986{ }^{[18]}$ à laquelle est ajoutée une grille de nylon (Polylabo, Strasbourg, France) tapissant la périphérie interne de la boîte de Pétri. La présence de la grille empêche la rétraction du lattis de collagène sous l'influence des cellules [19]. Le collagène utilisé au cours de nos expérimentations est du collagène de type I acido-soluble, issu de queue de rat. Les numérations cellulaires sont effectuées à l'aide d'un hématocytomètre de type Neubauer et le dosage de l'ADN est réalisé à l'aide d'une méthode fluorimétrique [20]. Pour toutes les lignées cellulaires, les expériences ont été réalisées en triplicate.

Pour l'observation en microscopie électronique à balayage, les lattis de collagène sont préparés selon la technique décrite par Lorimier et coll. en 1996 [20].

\section{Identification du récepteur S-Gal}

Les fibroblastes gingivaux humains sont ensemencés à 100000 cellules sur des lamelles de verre pla- cées au fond de puits de plaque 24 puits pendant 24 heures. Après rinçage au PBS, puis fixation dans une solution de paraformaldéhyde à $4 \%$ /PBS/ triton à $1 \%$, les cellules sont saturées dans un mélange PBS-SAB (Sérum Albumine Bovine) à $3 \%$ pendant une nuit à $4^{\circ} \mathrm{C}$. Les fibroblastes sont ensuite incubés dans du PBS $/ 1 \%$ SAB contenant un anticorps primaire polyclonal de lapin anti-V14 (dilution : 1 :25) (Proteogenix, Oberhausbergen, France) durant une heure à température ambiante, puis rinçage au PBS. Après incubation dans une solution de PBSSAB à $3 \%$ pendant 30 minutes, l'anticorps secondaire biotinylé de mouton anti-lapin IgG $(\mathrm{H}+\mathrm{L})$ (dilution : $1: 50$ ) (Immunotech, Marseille, France) est ajouté aux cellules pendant $30 \mathrm{~min}$, puis un mélange de streptavidine - Alexa 488 dilué au 1/2000 dans du PBS-SAB à $1 \%$ durant $10 \mathrm{~min}$. Les fibroblastes gingivaux sont enfin observés au microscope confocal (Biorad MRC600 Microscope, Zeiss Axiophot) à une longueur d'ondes de $488 \mathrm{~nm}$. S-Gal est également détecté par Western Blot en utilisant le même anticorps primaire polyclonal de lapin anti-V14. Des expériences identiques ont été effectuées avec des fibroblastes dermiques humains utilisés comme contrôle.

\section{Activation des fibroblastes gingivaux humains par les peptides d'élastine et analyses biochimiques}

Pour les analyses de RT-PCR, les ARNs totaux sont isolés à partir de 200000 fibroblastes gingivaux humains cultivés pendant 24 heures sur plastique en présence ou en l'absence de peptides d'élastine, et repris dans du Trizol ${ }^{\circledR}$ (Life Technologies, Pasley, Ecosse). La concentration en ARNs est déterminée par une mesure d'absorbance à $260 \mathrm{~nm}$. La RT-PCR est réalisée à partir de $1 \mu \mathrm{g}$ d'ARN total en utilisant un mastercycleur Eppendorf. Les amorces des différentes MMPs et urokinase sont obtenues auprès d'In Vitrogen (Fisher Block Scientific, Illkirch, France).

Les ADNs complémentaires sont amplifiés pendant 28,30 et 32 cycles selon les amorces utilisées. Les produits de PCR sont séparés sur un gel d'agarose à $1 \%(\mathrm{v} / \mathrm{v})$ contenant $5 \%$ de bromure d'éthidium. La fluorescence est évaluée à partir du gel à $312 \mathrm{~nm}$ et analysée par informatique (Vilbert, Lourmat, Marne la Vallée, France). médecine

buccale

chirurgie

buccale

VOL. $15, \mathrm{~N}^{\circ} 2$ 2009

page 77 
médecine

buccale

chirurgie

buccale

VOL. $15, \mathrm{~N}^{\circ} 2$ 2009

page 78
Pour l'identification des protéases et des TIMPs, des zymogrammes (électrophorèses à 10\% de polyacrylamide/ 0,1 SDS contenant de la gélatine et/ ou plasminogène) ou des zymoreverses sont utilisés respectivement [17].

Les protéines sont séparées par Western blot à partir des surnageants de culture sous conditions dénaturantes (1-4dithiotréitol) et transférées après électrophorèse, sur membrane de nitrocellulose (Immobilon P, Millipore, Bedford, MA, USA) [17]. Les membranes sont saturées avec $5 \%$ de TBST (Tris 0,05M, $\mathrm{NaCl} 0,15 \mathrm{M}, \mathrm{pH} 7,5$ ajusté avec de l'acide acétique $12 \mathrm{M}$ ) additionné de $5 \%$ de lait écrémé pendant 2 heures. Elles sont ensuite mises en contact avec l'anticorps primaire monoclonal [antiMMP1 humaine (Ab-1)/ anti-MMP3 humaine (Ab1)/ anti-TIMP1 humain (Ab-2)/ anti-TIMP2 humaine (Ab-4) ; Oncogen research products, Boston, MA, USA] dilué à une concentration de 1/1000 dans du TBST à $1 \%$ de lait écrémé pendant 1 nuit à $4^{\circ} \mathrm{C}$. Elles subissent alors 3 rinçages de 10 min dans du TBST pur, puis sont mises en contact avec l'anticorps secondaire polyclonal de mouton anti-souris (Immunotech, Marseille, France) dilué au $1 / 10000^{\circ}$ pendant 2 heures à température ambiante. Après 3 rinçages de $5 \mathrm{~min}$ au TBST et 3 rinçages de 5 min au TBS, le marquage est révélé par chemiluminescence grâce au kit ECL (RPN 2069) selon les instructions du fabricant (Amersham, Orsay, France). La dégradation des lattis de collagène est évaluée à partir du dosage du 4-hydroxyproline contenue dans les milieux de culture [20].

\section{Analyses statistiques}

Les expériences ont été réalisées avec 6 lignées cellulaires différentes; pour chacune d'entre elles, des triplicats ont été effectués et les données ont été analysées selon les tests de Student-Fisher. Une valeur de $p<0,05$ est considérée comme significative.

\section{RÉSULTATS}

\section{Stimulation de l'expression de MMP-3 par les peptides d'élastine passe par le récep- teur S-Gal}

En premier lieu, nous avons examiné par RT-PCR l'influence des peptides d'élastine sur l'expres- sion d'urokinase, des MMPs 1, 2, 3, 13, 14 et des TIMPs 1 et 2 par des fibroblastes gingivaux humains cultivés sur plastique pendant 24 heures. En présence des peptides, l'expression des ARNms de l'urokinase, MMP14, TIMP1 et TIMP2 demeure constante comparativement aux témoins sans peptides; seules des traces d'ARNm de MMP13 sont détectées. L'expression de MMP1 et MMP2 est légèrement augmentée. Au contraire, l'expression des ARNm de MMP3 est significativement augmentée en présence des peptides d'élastine (Fig. 1A).

Par analyses électrophorétiques (Western blot et zymogramme), les peptides d'élastine à une concentration de $100 \mu \mathrm{g} / \mathrm{mL}$ stimulent de façon significative la synthèse de MMP3 $(3,1 \pm 0,4$ fois plus en présence des peptides qu'en leur absence). La sécrétion de la MMP1 est aussi augmentée mais, à un degré moindre, et les niveaux de MMP2 ne sont pas significativement modifiés par la présence des peptides (Fig. 1B). Seules les formes inactives ou zymogènes sont détectées (Fig. 1C). La gélatinase B (MMP9) et la collagénase 3 (MMP13) ne sont pas détectées en l'absence ou en présence des peptides d'élastine et l'expression de MMP14 ne varie pas (non montré).

Le récepteur S-Gal des fibroblastes gingivaux humains est mis en évidence par immunomarquage et analyse confocale. II est réparti de façon homogène sur la membrane cellulaire et sa présence est aussi détectée à l'intérieur de la cellule (Fig. 2A). L'expression du récepteur a été également confirmée par Western blot où seule une bande de protéine possédant une masse moléculaire avoisinant $64 \mathrm{kDa}$ est identifiée (Fig. 2B). Pour évaluer l'implication de S-Gal dans la production de MMP3, les effets de peptides VGVAPG, VGVAPG3 et du lactose la production de MMP3 ont été évalués. La synthèse de cette enzyme est induite par les peptides VGVAPG bien qu'à un niveau inférieur à celui obtenu avec la kappa élastine (Fig. 2C).

Le lactose seul est capable d'augmenter la production de MMP3, mais une concentration de $10 \mu \mathrm{g} / \mathrm{ml}$ réduit l'induction de MMP3 par les cellules en présence des peptides d'élastine comparativement au contrôle sans peptides (Fig. 2C). 


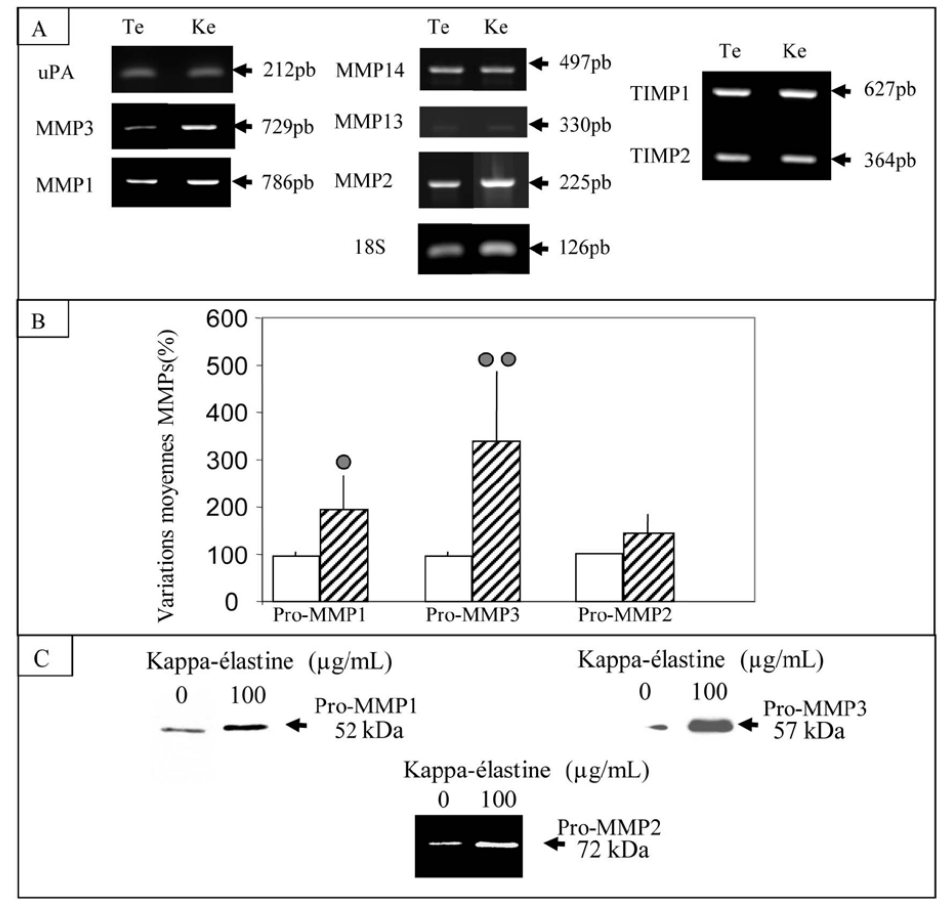

Figure 1 : Effets des peptides d'élastine sur l'expression des MMPs et de leurs inhibiteurs naturels, TIMPs 1 et 2. 200000 fibroblastes gingivaux humains sont cultivés à confluence pendant 24 heures en présence ou non de 100 mg/ml de kappa-élastine (kE) dans un milieu de culture sans sérum de veau fœtal. L'expression d'uPA, des différentes MMPs et de TIMPs-1 et -2 est analysée par RT-PCR (A). Te : contrôle cellulaire sans peptides d'élastine. L'expression protéique des MMPs1, 3, 2, est étudiée par Western blot et zymogramme (B, C). Les variations des MMPs-1, 2 et 3 sont représentatives de plusieurs expériences utilisant 6 lignées cellulaires différentes (B). Résultats significatifs par rapport au contrôle : $\bigcirc: \mathrm{p}<0.03 ; \bigcirc \bigcirc: \mathrm{p}<0.005$.

Effect of elastin peptides on the expression of MMPs and their natural inhibitors TIMPs 1 and 2.

200.000 human gingival fibroblasts were grown to confluence for 24 hours in the presence or absence of $100 \mu \mathrm{g} / \mathrm{ml}$ of kappa-elastin ( $k E$ ) in culture medium without serum fetal calf. The expression of uPA, various MMPs and TIMPs1 and 2 was analyzed by RT-PCR (A). Te: control cell without elastin peptides. The protein expression of MMPs1, 3, 2, is studied by western blot and zymogram $(B, C)$ Changes in MMP1, 2 and 3 are representative of several experiments using 6 different cell lines (B). Significant results compared to control: $\bigcirc: p<0.03 ; \bigcirc \bigcirc: p<0.005$.

\section{Influence des peptides d'élastine dans la collagénolyse}

Pour évaluer si la sur-régulation de la cascade protéolytique MMP3/MMP1 induite par les peptides d'élastine engendre une collagénolyse, on a utilisé des lattis de collagène de type I « attaché » ensemencés avec des fibroblastes gingivaux humains. Ces lattis sont assimilés à un milieu conjonctif en phase de remodelage. Dans ce type de culture sous tension, empêchant la contraction du collagène, la cascade protéolytique MMP3/MMP1 est largement réprimée [19]. Le fibroblaste gingival humain synthétise de façon constitutive des activateurs du plasminogène (UPA, tPA) [20]. L'activation de MMP3 pouvant dépendre de l'activité plasmine, les cultures sont complémentées (ou non) avec du plasminogène exogène à raison de $30 \mu \mathrm{g} / \mathrm{ml}$ (concentration proche de celle contenue dans les tissus) [21].

La production et l'activation de l'urokinase (UPA), révélées par la présence des formes actives à $40 \mathrm{kDa}$ et $33 \mathrm{kDa}$, sont similaires lorsque les lattis sont complémentés avec du plasminogène en présence ou en absence des peptides d'élastine (Fig. 3A). L'activité plasmine est maximale à 4 jours de culture et ne varie pas en l'absence ou en présence des peptides $(154,7 \mu \mathrm{U}$ et $156,1 \mu \mathrm{U}$, respectivement) (Fig. 3B). En l'absence de plasminogène, les peptides d'élastine augmentent la production de MMP3 (Fig. 3C) et, de façon non médecine

buccale chirurgie buccale

VOL. $15, \mathrm{~N}^{\circ} 2$ 2009

page 79 


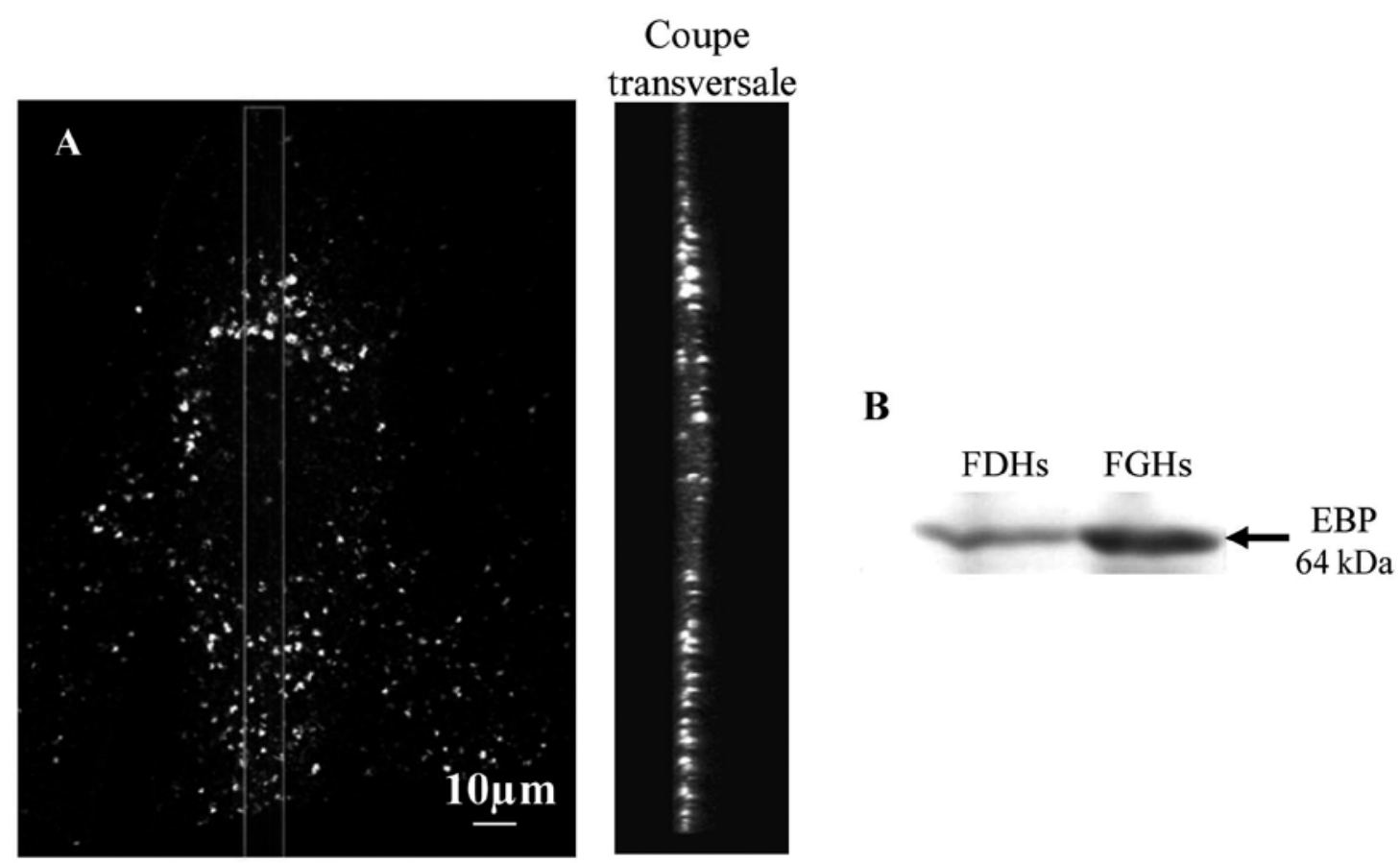

médecine

buccale

chirurgie

buccale

VOL. $15, \mathrm{~N}^{\circ} 2$ 2009

page 80

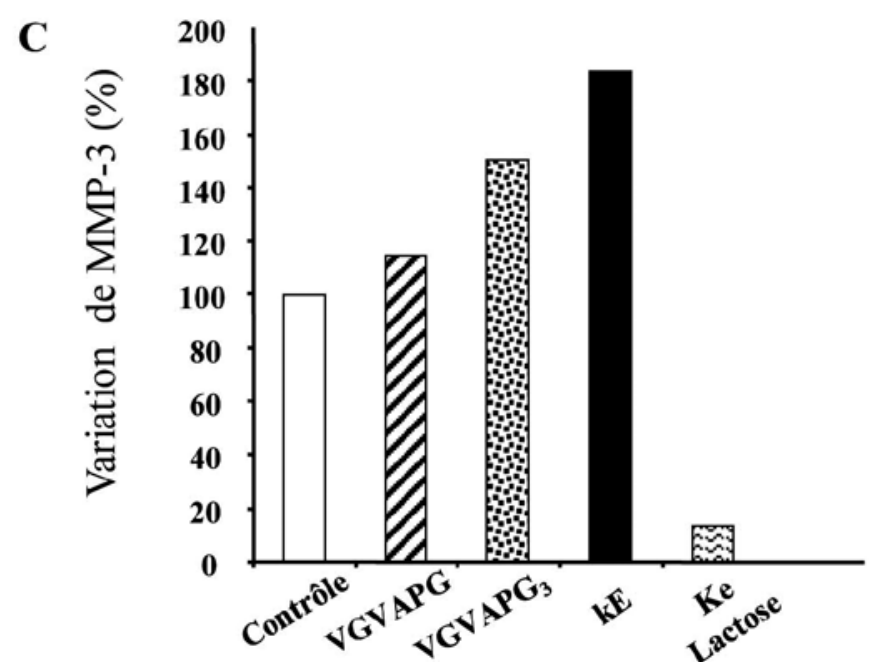

Figure 2 : L'expression de MMP3 par les fibroblastes gingivaux humains dépend du récepteur S-Gal ou « EBP ». La présence du récepteur S-Gal sur les fibroblastes gingivaux humains est mise en évidence par immunofluorescence assistée d'un microscope confocal (A) et par Western blot (B) en utilisant un anticorps anti-V14 correspondant à la région épissée $B$ galactosidase du récepteur $S-G a l$. Les membranes cellulaires des fibroblastes dermiques sont analysées parallèlement par Western blot (B). L'influence de VGVAPG, VGVAPG $3(200 \mu \mathrm{g} / \mathrm{ml}), \mathrm{de} \mathrm{kE} \mathrm{(100} \mathrm{\mu g/ml)}$ en présence ou non de lactose $(10 \mu \mathrm{g} / \mathrm{ml})$ sur l'expression de MMP3 (variation en \%) par les fibroblastes gingivaux humains est évaluée de façon semi-quantitative par Western blot (C). Ces données sont représentatives de deux lignées cellulaires fibroblastiques différentes.

The expression of MMP3 by human gingival fibroblasts depends on the S-Gal receptor or "EBP".

The presence of S-Gal receptor on human gingival fibroblasts is demonstrated by immunofluorescence assisted by a confocal microscope (A) and Western blot (B) using an antibody-V14 corresponding to the spliced region of B galactosidase S-Gal receptor. Cell membranes of dermal fibroblasts are analyzed in parallel by Western blot (B). The influence of VGVAPG, VGVAPG3 $(200 \mu \mathrm{g} / \mathrm{ml}), \mathrm{kE}(100 \mu \mathrm{g} / \mathrm{ml})$ in the presence or absence of lactose $(10 \mu \mathrm{g} / \mathrm{ml}) \mathrm{on}$ the expression of MMP3 (\% variation) by human gingival fibroblasts is measured on semi-quantitative Western blot (C). These data are representative of two different fibroblast cell lines. 


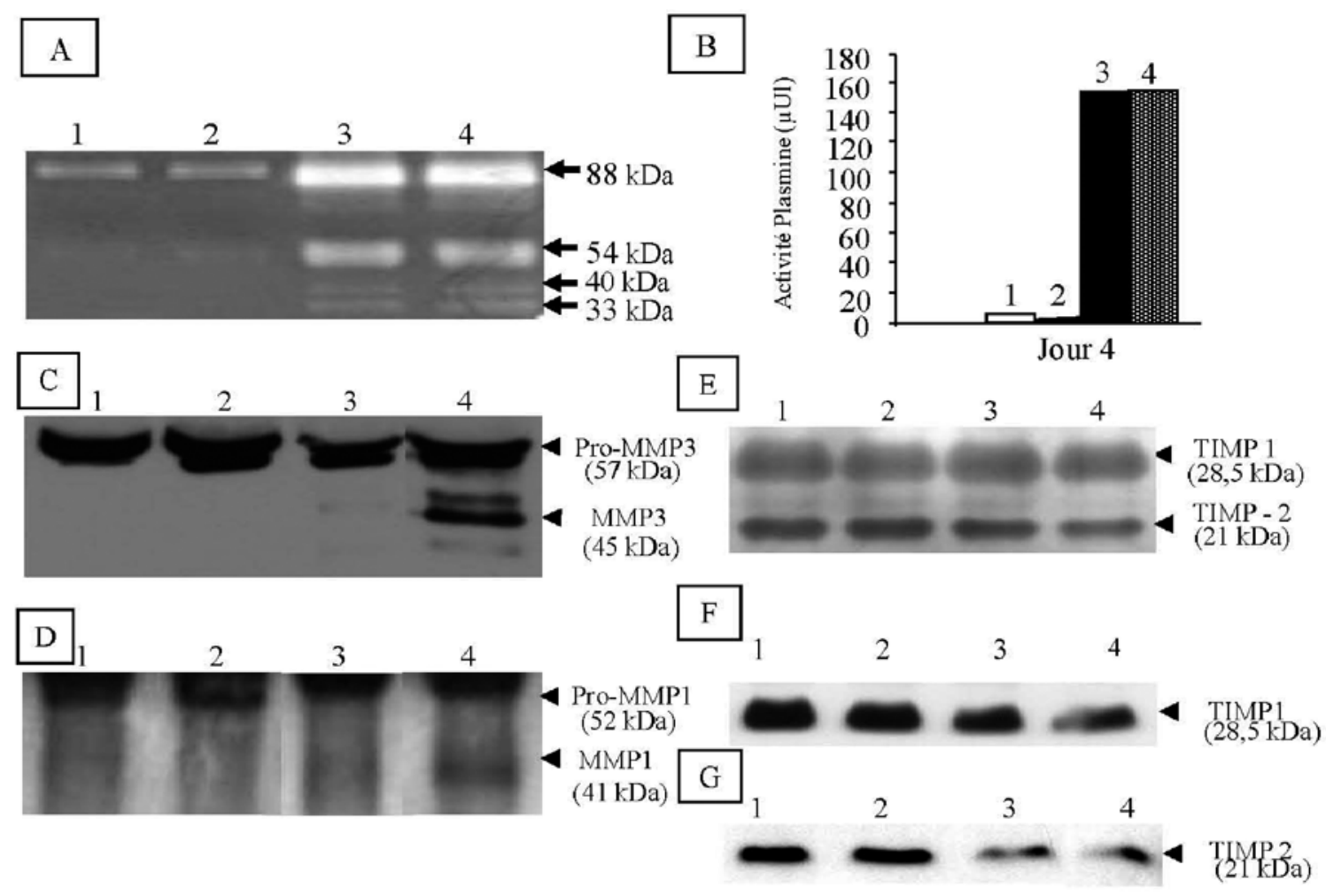

Figure 3 : Implication des peptides d'élastine dans la modulation du phénotype protéolytique de fibroblastes gingivaux humains cultivées ex vivo dans des lattis de collagène « attaché ».

L'influence des peptides d'élastine sur la modulation du phénotype protéolytique des fibroblastes gingivaux humains (200 000 cellules /lattis) est étudiée pendant 4 jours de culture.

Après 4 jours de culture, l'activité plasmine est déterminée à partir du substrat S2251 (B). L'expression d'uPA (A) et des différentes MMPs (MMP3, 1) (C, D) est analysée respectivement par zymogramme/plasminogène et Western Blot. L'expression de leurs inhibiteurs TIMPs 1 et 2 est évaluée par zymographie reverse (E) et Western blot (F, G) 1 : contrôle ; 2 : $\mathrm{kE}(100 \mu \mathrm{g} / \mathrm{ml})$; 3 : plasminogène $(30 \mu \mathrm{g} / \mathrm{ml}) ; 4$ : plasminogène $(30 \mu \mathrm{g} / \mathrm{ml})+\mathrm{kE}(100 \mu \mathrm{g} / \mathrm{ml})$. Ces expériences ont été réalisées en triplicate avec deux lignées cellulaires différentes.

Triggering of the plasmin/MMP3/MMP1 proteolytic cascade in elastin peptides (100 $\mu \mathrm{g} / \mathrm{ml})$-treated ex vivo attached gingival-fibroblast-populated collagen lattices.

The influence of elastin peptides on the proteolytic phenotype of human gingival fibroblasts (200,000 cells / lattice) is studied during 4 days of culture.

At 4 days of culture, plasmin activity was determined with 52251 as substrate (B). UPA (A) and different MMPs (MMP3, 1) $(C, D)$ were analyzed by zymogram / plasminogen and Western blott. TIMPs -1 and -2 were identified by reverse

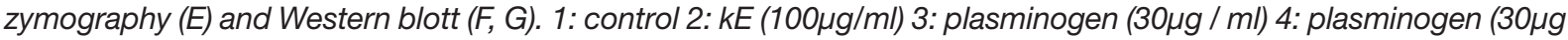
$/ \mathrm{ml})+\mathrm{kE}(100 \mu \mathrm{g} / \mathrm{ml})$. These experiments were performed in triplicate with 4 different cell lines.

significative, celle de la MMP1 (Fig. 3D). En présence de plasminogène, les peptides d'élastine exercent une influence majeure sur l'activation des pro-MMP3 (Fig. 3C) et pro-MMP1 (Fig. 3D), l'activation de la pro-MMP2 étant faiblement modifiée (non montrée). Parallèlement, ces peptides, en combinaison avec le plasminogène, diminuent le niveau de production des TIMPs1 et TIMPs2 (Fig. 3E, 3F, 3G). L'association peptides d'élastine et plasminogène augmente de façon significative la dégradation collagénique $(89+$ $8,2 \mathrm{ng}$ ) par rapport aux cultures sans ou avec un seul additif (Fig. 4A). Cette collagénolyse, observée en microscopie électronique à balayage, est associée à l'apparition de cavités de lyse matricielle dans l'environnement péricellulaire (Fig. 4B). Après 7 jours de culture, les lattis de collagène « attaché » et dégradés, ensemencés avec des fibroblastes gingivaux, se détachent de leur support spontanément (non montré).

\section{médecine buccale chirurgie buccale}

VOL. $15, \mathrm{~N}^{\circ} 2$ 2009

page 81 


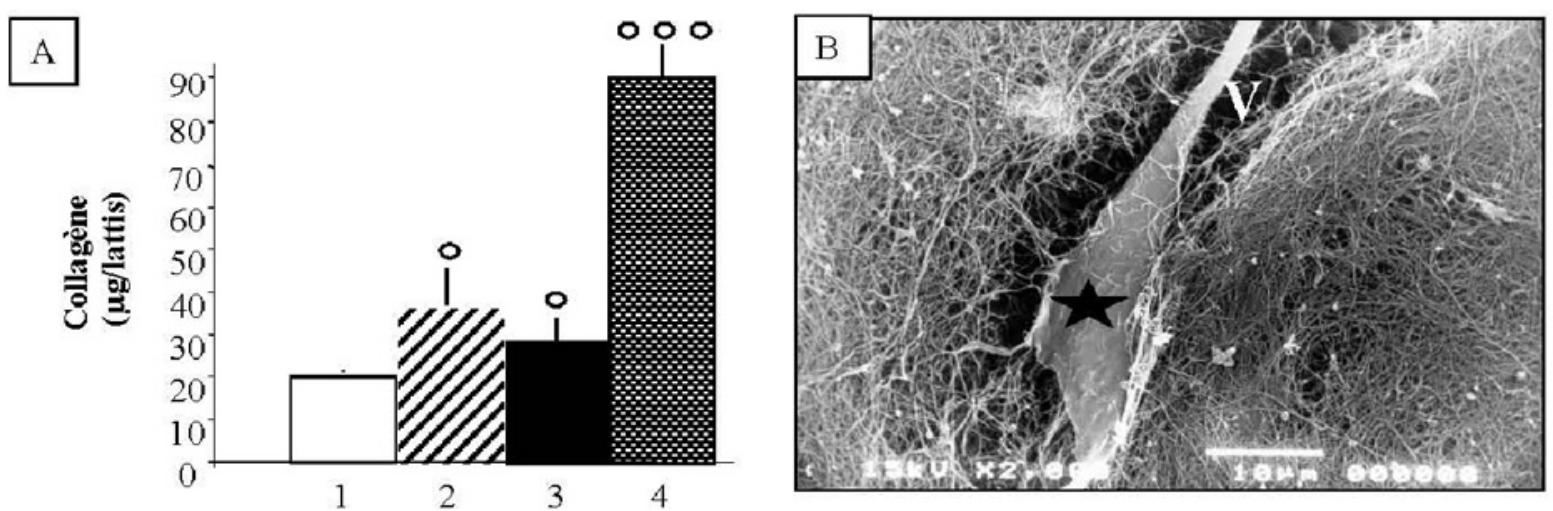

Figure 4 : Augmentation de la collagénolyse dans des lattis de collagène « attaché » ensemencés avec des fibroblastes gingivaux humains en présence de $100 \mu \mathrm{g} / \mathrm{ml}$ de peptides d'élastine (kE).

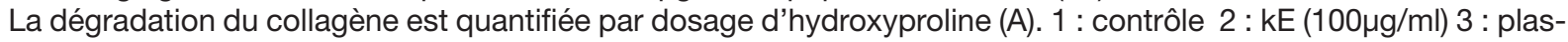
minogène $(30 \mu \mathrm{g} / \mathrm{ml}) 4$ : plasminogène $(30 \mu \mathrm{g} / \mathrm{ml})+\mathrm{kE}(100 \mu \mathrm{g} / \mathrm{ml})$. Les variations sont représentatives d'expériences réalisées en triplicate avec 4 lignées cellulaires différentes. Variations comparées au contrôle ${ }^{\circ}: p<0,05 ;{ }^{\circ}: p<0,01$; ${ }^{\circ}: \mathrm{p}<0,001$.

Les lattis sont observés en microscopie électronique à balayage (B). Après 4 jours de culture, les fibroblastes gingivaux humains, quelles que soient les conditions de culture, en présence ou absence de plasminogène (30 $\mu \mathrm{g} / \mathrm{ml})$, en présence ou absence de peptides d'élastine $(100 \mu \mathrm{g} / \mathrm{ml})$, possèdent une morphologie allongée typique ( $\star$ ), exhi-

médecine

buccale

chirurgie

buccale

VOL. $15, \mathrm{~N}^{\circ} 2$ 2009

page 82 bant une orientation parallèle à la surface du lattis (non montrée). La présence de cavités de lyse matricielle péricellulaire $(\mathrm{V})$ est essentiellement observée dans des lattis contenant à la fois, les peptides d'élastine et le plasminogène suggérant une collagénolyse localisée.

Increased collagenolysis in collagen lattice " attached » seeded with human gingival fibroblasts in the presence of kE $(100 \mu \mathrm{g} / \mathrm{ml})$.

Collagen degradation was quantified by hydroxyproline assay (A). 1: control 2: $\mathrm{kE}(100 \mu \mathrm{g} / \mathrm{ml})$ 3: plasminogen (30 $\mu \mathrm{g} / \mathrm{ml})$ 4: plasminogen $(30 \mu \mathrm{g} / \mathrm{ml})+k E(100 \mu \mathrm{g} / \mathrm{ml})$. The variations are representative of experiments performed in triplicate with 4 different cell lines. Significant results compared to the control ${ }^{\circ}: p<0.05,{ }^{\circ}: p<0.01,{ }^{\circ} \circ 0^{\circ}: p<0.001$.

The lattices are observed in scanning electron microscopy (B). After 4 days of culture, human gingival fibroblasts, irrespective of culture conditions in the presence or absence of plasminogen $(30 \mu \mathrm{g} / \mathrm{ml})$ in the presence or absence of elastin peptides $(100 \mu \mathrm{g} / \mathrm{ml})$ have a typically elongated morphology $(\star)$, showing an orientation parallel to the surface of the lattice (not shown). The presence of pericellular matrix lysis cavities $(\mathrm{V})$ is mainly observed in the lattice containing both elastin peptides and plasminogen suggesting located collagenolysis.

\section{DISCUSSION}

La destruction tissulaire au cours des parodontopathies est liée essentiellement à la sur-expression des métalloprotéinases ${ }^{[5]}$. Au sein de cette famille, la stromélysine 1 ou MMP-3, essentielle pour l'homéostasie tissulaire, est capable de cliver de nombreux constituants de la matrice extracellulaire et d'activer la collagènase 1 ou MMP1 $[4,7]$. Une étude clinique des fluides gingivaux a montré que le taux de MMP3 et du TIMP1 sont des marqueurs de la santé parodontale. Un taux de MMP3 élevé dans les poches parodontales sont liés à des risques de progression des parodontopathies [22]. Ce travail a démontré que les fragments d'élastine libérés sous l'action de l'élastase leucocytaire dans les sites inflammatoires, augmentent l'expression de la MMP3 dans des cultures de fibroblastes gingivaux humains. L'effet maximal est observé entre 50 à $100 \mu \mathrm{g} / \mathrm{ml}$ de peptides, concentration supérieure à celle du sang [23]. Bien que la tropoélastine se lie à l' $\alpha \mathrm{VB3}$ [24], la plupart des effets biologiques des peptides d'élastine passe par le récepteur S-Gal ${ }^{[9,16]}$. La présence cytosplasmique et membranaire du récepteur S-Gal dans les fibroblastes gingivaux a été révélée par immunofluorescence assistée de microscopie confocale. En effet, S-Gal agit soit comme récepteur cellulaire pour les peptides présentant la séquence consensus GXXPG, soit 
comme protéine chaperonne dirigeant l'assemblage extracellulaire de la tropoélastine au sein des fibres élastiques mâtures ${ }^{[14]}$.

Le lactose et les peptides VGVAPG pouvant respectivement inhiber et reproduire les effets des peptides d'élastine sur la sur-expression de MMP3, il a été démontré que ces effets passent par le récepteur S-Gal. Ce dernier est exprimé de façon ubiquitaire par plusieurs types cellulaires en culture avec un effet sur l'expression des MMPs qui peut être différent selon les cellules. La liaison de l'élastine à S-Gal entraîne une augmentation de la production et de l'activation de MT1-MMP et de MMP2 aussi bien par les mélanocytes que pour les cellules endothéliales alors qu'elle n'a pas ou peu d'influence sur la production des autres MMPs [13, 25]. Dans des lignées de fibrosarcome, HT1080, MT1-MMP, MMP-2, MMP1 et TIMPs sont sur-exprimés sous l'action des peptides d'élastine [17]. Dans les cultures de fibroblastes dermiques, les peptides d'élastine induisent une sur-expression de MMP1 comparable à celle de MMP3 [11] ; dans des cultures de fibroblastes gingivaux humains, ils agissent préférentiellement sur la production de MMP3. De telles différences entre types cellulaires ne sont pas expliquées bien que l'induction enzymatique par les peptides soit associée fréquemment à l'activation de la voie de signalisation Erk 1/2 [11].

L'induction de la cascade protéolytique plasmine/MMP3/MMP1 nécessite à la fois une expression cellulaire des activateurs du plasminogène et une concentration des enzymes actives supérieure à celle de leurs inhibiteurs naturels, les TIMPs. L'environnement tridimensionnel physiologique cellulaire a été reproduit au mieux grâce à des cultures de lattis de collagène sous tension ou « attaché », ensemencés avec des fibroblastes gingivaux ${ }^{[19,26]}$. Cet équivalent du tissu conjonctif gingival présente des avantages par rapport au modèle dermique. Les fibroblastes gingivaux synthétisent de façon constitutive des activateurs du plasminogène (uPA, tPA), enzyme clef dans les cascades protéolytiques [20] : le milieu de culture a donc été complémenté avec du plasminogène exogène à une concentration avoisinant celle retrouvée dans les tissus [21] ; sa transformation en plasmine, puissant activateur de MMPs comme la MMP3, active en cascade la MMP1 aux propriétés collagénolytiques ${ }^{[7]}$.

Quand les cellules sont maintenues sous tension au sein des lattis de collagène « attaché ", elles adoptent un phénotype anabolique avec répression de l'expression des protéases et, par conséquent, du turn-over collagénique [19]. La collagénolyse est faible quand les lattis sont réalisés en l'absence de peptides d'élastine. A l'inverse, en présence des peptides d'élastine et de plasminogène, le comportement des fibroblastes gingivaux est proche de celui observé dans des lattis de collagène « flottant » ou rétractable (non montré). Après quatre jours de culture, la différence du taux de collagénolyse au sein des lattis de collagène " attaché » en comparaison avec celui des lattis de collagène « flottant " $(89+$ $8,2 \mu \mathrm{g}$ de collagène pour $223+20 \mu \mathrm{g}$, respectivement) souligne le rôle potentiel de S-Gal comme mécano-récepteur.

Dans ces conditions expérimentales, l'influence des peptides d'élastine sur la collagénolyse est clairement attribuée à une activation de la cascade protéolytique plasmine/MMP3/MMP1 alors que la production et l'activation de MMP2 restent stables en l'absence ou en présence des peptides d'élastine dans les cultures complémentées en plasminogène. Bien que la MMP13 soit induite dans ce modèle de culture, les peptides d'élastine n'ont aucune influence sur son expression (non montré). L'expression des collagènases dépend de l'activation des voies de signalisation : l'activation de p38 est nécessaire à l'induction de MMP13[27] alors que l'expression de la MMP3, aussi bien que celle de la MMP1 passant par SGal, est associée à une activation de la voie Erk 1/2 [11].

L'augmentation de la collagénolyse peut résulter de la sous-production des inhibiteurs TIMPs1 et TIMPs2, observée en culture, en présence de plasminogène seul, amplifié lors de l'association plasminogène - peptides d'élastine. Le niveau des ARNm des TIMPs restant constant en présence ou en absence des peptides d'élastine, un mécanisme de contrôle des TIMPs est donc posttranscriptionnel. La dégradation du TIMP1 peut être induite par la plasmine générée en culture, mais ces inhibiteurs sont peu ou faiblement hydro- médecine

buccale

chirurgie

buccale

VOL. $15, N^{\circ} 2$ 2009

page 83 
médecine buccale chirurgie buccale

VOL. $15, \mathrm{~N}^{\circ} 2$ 2009

page 84 lysés par celle-ci [28]. Des cellules de mélanome cultivées dans des lattis de collagène conduisent à une disparition marquée du TIMP2 [25] qui peut être attribuée à une internalisation et une dégradation du TIMP2 dépendant de la MMP14 comme cela a été décrit pour d'autres lignées tumorales [29].

L'hypothèse que la collagénolyse serait induite par l'élastolyse a été vérifiée ex vivo dans des modèles équivalents à la lamina propria gingivale. L'analyse des données de la littérature suggère que l'élastase leucocytaire joue un rôle indéniable dans la genèse des parodontopathies [30]. Les peptides d'élastine résultant de l'élastolyse pourraient agir soit comme amplificateurs de la production de l'élastase leucocytaire, soit en fonction de ce qui vient d'être démontré ex vivo dans un équivalent du tissu conjonctif gingival, comme inducteurs de la cascade protéolytique MMP1/MMP3 et de la collagénolyse. Toutefois, en fonction de la concentration des peptides d'élastine libérés au sein du sulcus ou de la poche inflammatoire, les études ultérieures in vivo ou ex vivo devront déterminer si le concept de la « collagénolyse induite par l'élastolyse " conduit à une phase de réparation/remodelage tissulaire ou s'il participe à la destruction matricielle observée au cours des maladies parodontales.

Enfin, les inflammations parodontales, initialement gingivales donc superficielles, peuvent s'étendre en profondeur et toucher l'os alvéolaire. Le contact de l'os alvéolaire avec l'inflammation de la gencive suggère que les peptides issus de l'élastolyse gingivale peuvent moduler le comportement des éléments constitutifs de l'os, plus particulièrement les cellules osseuses. Aussi, de nouvelles recherches permettront d'établir le rôle éventuel des peptides d'élastine dans la physiopathologie osseuse.

Remerciements : Ce travail a été réalisé grâce aux soutiens de l'unité INSERM UMR-S 926 et de l'unité CNRS UMR 6237.

\section{RÉFÉRENCES}

1 - Darveau RP, Tanner A, Page RC. The microbial challenge in periodontitis. Periodontol 20001997 ; 14 : 12-32.

2 - Schenken HA. Host responses in maintaining periodontal health and determining periodontal disease. Periodontol 20002006 ; 40 : 77-93.

3 - Kornman KS, Page RC, Tonetti M. The host response to the microbial challenge in periodontitis assembling the players. Periodontol 20001997 ; 14 : 33-53.

4 - Murphy G, Nagase H. Progress in matrix metalloproteinase research. Mol Aspects Med 2008 ; 29 : 290 308.

5 - Cox SW, Eley BM, Asikainen A, Tervahartiala T, Sorsa T. Collagen degradation by interleukin 1B-stimulated gingival fibroblasts is accompanied by release and activation of multiple matrix metalloproteinases and cysteine proteinases. Oral Dis 2006 ; 12 : 34-40.

6 - Overall CM, Wiebkin OW, Thonard JC. Demonstration of tissue collagenase activity in vivo and its relationship to inflammation severity in human gingiva. J Periodont Res $1987 ; 22: 81-8$

7 - Ra HJ, Parks WC. Control of matrix metalloproteinase catalytic activity. Matrix Biol 2007 ; 26 : 587-96.

8 - Uitto VJ. Gingival crevice fluid. Periodontol 2000. 2003 ; $31: 9-11$.
9 - Antonicelli F, Bellon G, Debelle L, Hornebeck W. Elastinelastases and inflamm-aging. Curr Top Dev Biol 2007 ; $79: 99-155$.

10 - Eijel AL, Igondjo-Tchen S, Ghomrasseni S, Pellat B, Godeau G, Gogly B. Expression of matrix metalloproteinases (MMPs) and tissue inhibitors of metalloproteinases (TIMPs) in healthy and diseased human gingiva. J Periodontol 2003 ; 74 : 188-95.

11 - Duca L, Debelle L, Debret R, Antonicelli F, Hornebeck W, Haye B. The elastin peptides-mediated induction of procollagenase- 1 production by human fibroblasts involves activation of MEK/ERK pathway via PKA- and $\mathrm{PI}_{3} \mathrm{~K}$ dependent signalling. FEBS Lett 2002 ; 524 : 193-8.

12 - Debret R, Antonicelli F, Theill A, Hornebeck W, Bernard P, Guenounou M, Le Naour R. Elastin-derived peptides induce a T-Helper type I polarization of human blood lymphocytes. Arterioscler Thromb Vasc Biol $2005 ; 25: 1353-8$.

13 - Robinet A, Fahem A, Cauchard JH, Huet E, Vincent L, Lorimier S, Antonicelli F, Soria C, Crepin M, Hornebeck W, Bellon G. Elastin-derived peptides enhance angiogenesis by promoting endothelial cell migration and tubulogenesis through up-regulation of membrane-type metalloproteinase 1 (MT1-MMP). J Cell Sci $2005 ; 118$ : 343-56. 
14 - Brassart B, Fuchs P, Huet E, Alix AJP, Wallach J, Tamburro AM, Delacoux F, Haye B, Emonard H, Hornebeck W, Debelle L. Conformational dependence of collagenase (matrix metalloproteinase-1) up-regulation by elastin peptides in cultured fibroblasts. J Biol $2001 ; 276: 5222-7$.

15 - Booms P, Ney A, Barthel F, Moroy G, Counsell D, Gille C, Guo G, Pregla R, Mundlos S, Alix AJP, Robinson $P N$. A fibrillin-I-fragment containing the elastin-bindingprotein GXXPG consensus sequence upregulates matrix metalloproteinase-1: biochemical and computational analysis. J Mol Cell Cardiol 2006 ; 40 : 234-46.

16 - Hinek A. Biological roles of the non-integrin elastin/laminin receptor. Biol Chem 1996 ; 377 : 471-80.

17 - Brassart B, Randoux A, Hornebeck W, Emonard H. Regulation of matrix metalloproteinase-2 (gelatinase A, MMP-2), membrane-type matrix metalloproteinase-1 (MT1-MMP) and tissue inhibitor of metalloproteinases2 (TIMP-2) expression by elastin-derived peptides in human HT- 1080 fibrosarcoma cell line. Clin Exp Metastasis $1998 ; 16: 489-500$.

18 - Gillery P, Maquart FX, Bore1 JP. Fibronectin dependence of the contraction of collagen lattices by human skin fibroblasts. Exp Cell Res 1986 ; 167 : 29-37.

19 - Lambert CA, Colige AC, Munaut C, Lapiere CM, Nusgens BV. Distinct pathways in the over-expression of matrix metalloproteinases in human fibroblasts by relaxation of mechanical tension. Matrix Biol 2001;20:397-408.

20 - Lorimier S, Gillery P, Hornebeck W, Chastang F, LaurentMaquin D, Bouthors S, Droulle C, Potron G, Maquart FX. Tissue origin and extracellular matrix control neutral proteinase activity in human fibroblast three-dimensional cultures. J Cell Physiol 1996 ; 168 : 188-98.

21 - Vassali JD, Sappino AP, Belin D. The plasminogen activator/plasmin system. J Clin Invest 1991 ; 88 : 1067 72.

22 - Alpagot T, Bell C, Lundergan W, Chambers DW, Rudin R. Longitudinal evaluation of GCF MMP-3 and TIMP-1 levels as prognostic factors for progression of periodontitis. J Clin Periodontol $2001 ; 28$ : 353-9.
23 - Tsuruga E, Irie K, Sakakura Y, Yajima T. Tropoelastin expression by periodontal fibroblasts. J Dent Res 2002 ; 81: 198-202.

24 - Rodgers UR, Weiss AS. Integrin $\alpha \mathrm{V} \beta_{3}$ binds a unique non-RGD site near the C-terminus of human tropoelastin. Biochimie 2004;86:173-8.

25 - Ntayi C, Labrousse AL, Debret R, Birembaut P, Bellon G, Antonicelli F, Hornebeck W, Bernard P. Elastin-derived peptides upregulate matrix metalloproteinase-2mediated melanoma cell invasion through elastin-binding protein. J Invest Dermatol 2004 ; 122 : 256-65

26 - Dallon JC, Ehrlich HP. A review of fibroblast-populated collagen lattices. Wound Repair Regen 2008 ; 16 : 4729.

27 - Ravanti L, Heino J, Lopez-Otin C, Kähäri VM. Induction of collagenase-3 (MMP-13) expression in human skin fibroblasts by three-dimensional collagen is mediated by p38 mitogen-activated protein kinase. J Biol Chem $1999 ; 274: 2446-55$.

28 - Okada Y, Watanabe S, Nakanishi I, Kishi Jl, Hayakawa T, Watorek W, Travis J, Nagase H. Inactivation of tissue inhibitor of metalloproteinases by neutrophil elastase and other serine proteinases. FEBS Lett 1988 ; 229 : 157-60.

29 - Maquoi E, Frankenne F, Baramova E, Munaut C, Sounni NE, Remacle A, Noël A, Murphy G, Foidart JM Membrane type 1 matrix metalloproteinase-associated degradation of tissue inhibitor of metalloproteinase 2 in human tumor cell lines. J Biol Chem 2000 ; 275 : 11368-78.

30-Meyer J, Guessous F, Huynh C, Godeau G, Hornebeck W, Giroud JP, Roch-Arveiller M. Active and $\alpha$-1 proteinase inhibitor complexed leukocyte elastase levels in crevicular fluid from patients with periodontal diseases. J Periodontol 1997 ; 68 : 256-61.

\section{médecine buccale chirurgie buccale \\ VOL. $15, \mathrm{~N}^{\circ} 2$ 2009}

page 85 